Rowan University

Rowan Digital Works

$1-2016$

\title{
The Impact of Perceived Subgroup Formation on Transactive Memory Systems and Performance in Distributed Teams
}

Yide Shen

Rowan University, shen@rowan.edu

M. J. Gallivan

X. Tang

Follow this and additional works at: https://rdw.rowan.edu/business_facpub

Part of the Business Administration, Management, and Operations Commons

\section{Recommended Citation}

Shen, Y., Gallivan, M. J., \& Tang, X. (2016). The Impact of Perceived Subgroup Formation on Transactive Memory Systems and Performance in Distributed Teams. International Journal of e-Collaboration, 12 (1), 44-66.

This Article is brought to you for free and open access by the Rohrer College of Business at Rowan Digital Works. It has been accepted for inclusion in Rohrer College of Business Faculty Scholarship by an authorized administrator of Rowan Digital Works. 


\title{
The Impact of Perceived Subgroup Formation on Transactive Memory Systems and Performance in Distributed Teams
}

\author{
Yide Shen, Department of Marketing and Business Information Systems, Rowan Unviersity, Glassboro, NJ, USA \\ Michael J. Gallivan, Department of Computer Information Systems, Georgia State University, Atlanta, GA, USA \\ Xinlin Tang, Department of Entrepreneurship, Strategy, and Information Systems (ESIS), Florida State University, \\ Tallahassee, FL, USA
}

\begin{abstract}
With distributed teams becoming increasingly common in organizations, improving their performance is a critical challenge for both practitioners and researchers. This research examines how group members' perception of subgroup formation affects team performance in fully distributed teams. The authors propose that individual members' perception about the presence of subgroups within the team has a negative effect on team performance, which manifests itself through decreases in a team's transactive memory system (TMS). Using data from 154 members of 41 fully distributed teams (where no group members were colocated), the authors found that members' perceptions of the existence of subgroups impair the team's TMS and its overall performance. They found these effects to be statistically significant. In addition, decreases in a group's TMS partially mediate the effect of perceived subgroup formation on team performance. The authors discuss the implications of their findings for managerial action, as well as for researchers, and they propose directions for future research.
\end{abstract}

\section{KEYWORDS}

Distributed Teams, Subgroup Formation, Subgroups, TMS, Transactive Memory

\section{INTRODUCTION}

Distributed teams, also known as dispersed teams or virtual teams, refer to groups comprised of members from different locations who collaborate online toward a common goal (Oshri, van Fenema, $\&$ Kotlarsky, 2008). By using information and communication technologies, distributed teams perform tasks such as product development, software development, and strategic planning in organizations (Kotlarsky \& Oshri, 2005; Maruping, Zhang, \& Venkatesh, 2009; Thomas \& Bostrom, 2010). With the rapid growth of globalization, combined with cost-cutting, cross-functional projects and mobility, distributed teams are now common in organizations (Fuller, Hardin, \& Davison, 2006; Gressgard, 2011; Jarvenpaa, Shaw, \& Staples, 2004; Mahfooz, 2011; Majchrzak, Malhotra, \& Lipnack, 2004; Purvanova \& Bono, 2009). For example, a 2012 Society for Human Resource Management (SHRM) survey found that 46 percent of firms use virtual teams (Geller, Lee, Alonso, Schmit, \& Esen, 2012). Another recent survey on "Trends in Global Virtual Teams" reported that 40 percent of nearly 3,000 survey respondents spend between half and all of their time working on multicultural virtual teams (RW CultureWizard, 2014). 
Despite the proliferation of distributed teams in organizations, studies show that it is inherently challenging to achieve team effectiveness in distributed environments, due to temporal, geographic, and cultural differences (Espinosa, Slaughter, Kraut, \& Herbsleb, 2007; Kotlarsky \& Oshri, 2005; Mukherjee, Lahiri, Mukherjee, \& Billing, 2012; Sarker, Ahuja, Sarker, \& Kirkeby, 2011). Respondents to the "Trends in Global Virtual Teams" survey report that compared to face-to-face teams, it is more challenging to make decisions (55 percent), manage conflict (54 percent), or express opinions (53 percent) in distributed teams (RW CultureWizard, 2014). Since information technology alone is not sufficient to bridge these reported challenges in distributed teams (Duranti \& de Almeida, 2012; Kotlarsky \& Oshri, 2005; Oshri et al., 2008), there are calls for research on the social aspects of these teams to improve their effectiveness (Kotlarsky, van Fenema, \& Willcocks, 2008; Orlikowski, 2002).

To date, existing studies have focused mainly on positive social aspects of virtual teams, such as trust, social ties, rapport, communication patterns, and formal and informal communication, which improve virtual team outcomes (Glückler \& Schrott, 2007; Jarvenpaa \& Leidner, 1999; Kiesler \& Cummings, 2002; Kraut \& Streeter, 1995; Lowry, Zhang, Zhou, \& Fu, 2010; Storck \& Hill, 2000). Fewer studies, however, have examined the social factors that negatively affect team performance in virtual environments, which limits our ability to reduce and mitigate their impacts on team performance. To complement our understanding of the positive social factors that are essential to the success of distributed teams, we focus on negative social aspects of virtual teams. Specifically, we examine the effect of perceived subgroup formation, a factor that has been found to negatively affect team effectiveness in traditional face-to-face team settings (Carton \& Cummings, 2012; Cronin, Bezrukova, Weingart, \& Tinsley, 2011), but has received limited attention in distributed teams.

When a team consists of multiple members, there is the potential for the team to split into subgroups, based on one or more factors such as demographic characteristics (Cramton \& Hinds, 2005; Homan et al., 2008), the existence of prior relationships among certain members (Polzer, 2004), as well as members' attitude and beliefs (Harrison, Price, \& Bell, 1998). While the impact of subgroup formation within group is well documented in the face-to-face context (Gibson \& Vermeulen, 2003; Jehn \& Bezrukova, 2010), its impact on the performance of distributed teams has not been thoroughly examined. This lack of attention to subgroup formation may be due to researchers' beliefs that demographic attributes - which are typically the cause of such subgroups - are less salient or noticeable in fully distributed teams, where each member resides in a different location. We argue that subgroups can emerge in a fully distributed team, although the causes may be unrelated to demographic traits like age, race, or location. Previous studies show that while there may be many factors that contribute to subgroup formation in face-to-face teams or distributed teams, what truly matters is team members' perceptions of subgroup formation (Cronin et al., 2011). Since the objective attributes are less salient in a distributed environment, we propose that members' perceptions of subgroups is a critical factor that will influence team interaction and performance outcomes.

We draw on the literature of knowledge management, especially transactive memory systems (TMS), to understand the mechanisms through which members' beliefs about subgroups affect team performance. The phrase transactive memory system describes team members actively using their collective knowledge of "who knows what" to complete a team task collaboratively. It is considered to be an important "team cognitive process" (Zhang, Hempel, Han, \& Tjosvold, 2007) that is especially critical for knowledge intensive teams that seek to achieve high performance (Lewis, 2004). Distributed teams can effectively access diverse expertise across geographic locations (Majchrzak et al., 2004). Thus, the performance of distributed team depends, to a great extent, on a group's active management of its knowledge and expertise (Herbsleb, Mockus, Finholt, \& Grinter, 2000; Herbsleb \& Moitra, 2001). However, in a distributed environment, it is inherently difficult for team members to learn what other members know, due to a lack of face-to-face communication and personal interaction 
(Armstrong \& Cole, 1995; Cramton, 2001; Espinosa, Slaughter, Herbsleb, \& Kraut, 2007; Griffith \& Neale, 2001; Kotlarsky \& Oshri, 2005; Sole \& Edmondson, 2002). The existence of subgroups can potentially increase the challenges for distributed teams to form highly developed TMSs. Therefore, we propose TMS is an important mechanism through which members' beliefs about the existence of subgroups affects the entire team's performance. In doing so, we respond to recent calls for more research that examines the effect of team composition inputs, such as subgroups, on TMS (Lewis \& Herndon, 2011).

By integrating research on subgroup formation and TMS, this study contributes to the literature in three ways. First, it moves beyond subgroups based on geographic location to further our understanding of the effect of perceived subgroup formation on team performance in fully distributed teams. Second, we identify a potential team-level mediator - TMS - that plays an important role between perceived subgroup formation and team performance in distributed environments. Finally, we extend the TMS literature by examining how subgroup dynamics affect TMS in distributed teams, which is a research gap that has yet to be addressed.

\section{THEORETICAL BACKGROUND AND HYPOTHESES}

Extensive research that analyzes the influence of subgroups on team processes and outcomes in faceto-face teams has been conducted. Results generally support the expectation that strong subgroup divisions can impair team processes (e.g., communication, group efficacy, and team identity) as well as outcomes (e.g., performance, team satisfaction) (Cronin et al., 2011; Earley \& Mosakowski, 2000; Li \& Hambrick, 2005; Molleman, 2005; Ramon Rico, Molleman, Sanchez-Manzanares, \& Vegt, 2007). In contrast to studies of face-to-face teams, however, we know little about subgroups in fully distributed teams, where no members are physically colocated.

Thus, we propose to extend the established frameworks regarding subgroups and their negative effects to distributed environments from two perspectives. First, we introduce the notion of perceived subgroup formation, which is defined as members' perceptions of fragmentation within the team that the team has actually experienced - as opposed to the conventional notion of subgroups, which is defined as a function of members' geographic locations. Second, we posit that TMS is a critical mechanism that mediates the effect of perceived subgroup formation on performance in distributed teams. Figure 1 presents our proposed model. The rest of section 2 discusses the theoretical background and hypotheses development.

Figure 1. Research model

$\mathrm{H} 1$

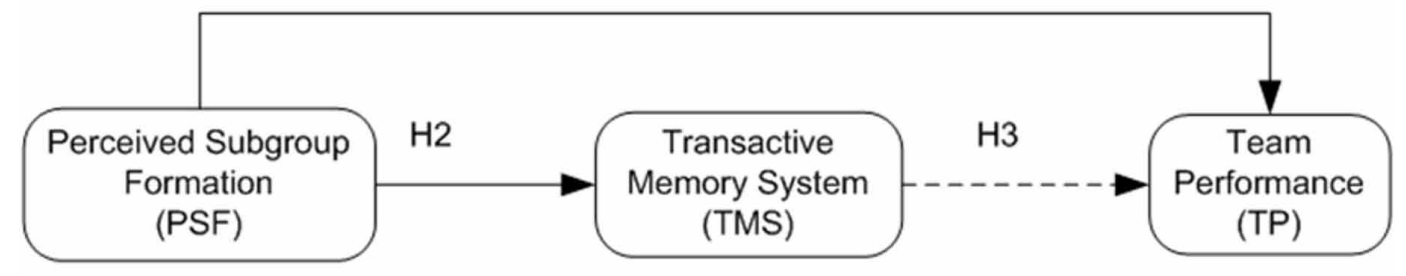

$\longrightarrow$ Direction relationship

$---\rightarrow$ Mediating relationship between PSF, TMS and TP 


\section{Perceived Subgroup Formation}

The existence of subgroups is quite common and typically emerges within larger teams. This phenomenon has drawn ongoing attention among scholars who study team effectiveness, since the emergence of distinct subgroups within a larger team is known to impair coordination, trust, and information-sharing among team members (Cramton \& Hinds, 2005; Phillips, Mannix, Neale, \& Gruenfeld, 2004; Polzer, 2004; Polzer, Crisp, Jarvenpaa, \& Kim, 2006). In studying how subgroup formation affects distributed teams, scholars have focused solely on defining subgroups by geographic location, i.e., members who are colocated in the same location are assumed to represent a subgroup. For example, Polzer and colleagues (2006) compared fully distributed teams and teams with some colocated members and found that fully distributed teams experienced less conflict and higher levels of trust, relative to the partially-distributed teams. Likewise, O'Leary and Mortensen (2010) showed that teams with geographically isolated members with no teammates at their location have better team outcomes than those for which subgroups exist at different locations. Both studies showed that when analyzing subgroup dynamics in distributed teams, the geographic configuration of members is a critical factor.

When considering fully distributed teams, however, geographical factors are less relevant, since each member in a fully distributed team resides at a different location. In addition, focusing only on geographic configuration cannot account for team members' beliefs about the existence of subgroups. Whether in face-to-face teams or in distributed teams, what truly matters is team members' perceptions about the existence of subgroups (Cronin et al., 2011), rather than subgroups assumed to exist due to demographic traits (in the face-to-face team literature) or physical location (in the distributed team literature). In fact, research on subgroups has shown that differences based on members' demographic attributes (e.g., race and gender) do not necessarily trigger the true internal team divisions that members actually experience (Jehn \& Bezrukova, 2010).

Thus, there is a distinction between subgroups based on team composition input (e.g., geographic configuration, members' demographic attributes) and subgroups that are actually experienced by team members. Such a distinction is especially critical in distributed teams. Although real-time audio and video communication are prevalent in distributed teams, since team members do not interact in person as often as in face-to-face teams, visible demographic features are less observable in distributed teams. Instead, other attributes may become important in distributed teams. For example, studies of globally distributed teams discovered that members who shared a similar occupational culture were able to overcome nationality differences and thus perform effectively (Elron \& Shamir, 1999; Maznevski \& DiStefano, 2000; Snow, Snell, Davison, \& Hambrick, 1996). Bhappu et al. (1997) found that group membership based on demographic features (e.g., gender) biased the amount of attention that members paid to in-group (same sex) versus out-group (opposite sex) team members in face-to-face teams. However, this bias was absent in teams that only used electronic media to communicate, even when a person's gender was readily identifiable (Bhappu et al., 1997).

As a result, focusing only on subgroups based on team composition factors (e.g., geographic configuration, members' demographic attributes) may limit our understanding of the effects of subgroups on fully distributed teams. Therefore, in this study, we focus on members' perceptions of the existence of subgroups and their downstream effects on factors such as the group's transactive memory system and its performance.

Prior research conducted with face-to-face teams suggests that the more deeply members perceive subgroup divisions, the worse a team's performance and member satisfaction (Cronin et al., 2011; Earley \& Mosakowski, 2000). The rationale is that a high level of perceived subgroup formation is likely to expose subgroups to frustration, anxiety and even hostility by members of other subgroup. This can create a "vicious cycle" of conflict among subgroups (Lipponen, Kelkama, \& Juslin, 2003; Polzer et al., 2006), which, in turn, causes members to avoid open communication and full informationsharing with members of other subgroups. 
A decade of research on knowledge management recognizes that effective coordination depends on members sharing a common understanding of the task at hand, clear norms of behavior, and a shared context for interpreting information (Davenport \& Prusak, 1997; Dougherty, 1992; Krauss \& Fussell, 1990). However, team members located in distinct locations are more likely to "experience different exogenous events, physical settings, constraints and practices, resulting in their having different information, assumptions, preferences and constraints" (Cramton \& Hinds, 2005, p. 236). For distributed teams to achieve high performance, bridging such contextual differences and building common ground with regard to shared assumptions and information is quite critical (Bjørn \& Ngwenyama, 2009; Cramton, 2001; Malhotra \& Majchrak, 2004; Olson \& Olson, 2000). When a "us vs. them" mentality exists within a team, its members tend not to communicate or share information fully (Jehn \& Bezrukova, 2010). Without adequate communication across the full team, members are less likely to develop a shared understanding of their task and its context. All of these will hurt team performance. Therefore, we posit:

Hypothesis 1: Perceived subgroup formation is negatively related to team performance in fully distributed teams.

\section{Transactive Memory System (TMS)}

To understand the mechanisms through which subgroup formation affects team performance, we draw on the knowledge management literature, specifically the literature on transactive memory systems (TMS). Transactive memory refers to the knowledge that a person has about what another person knows. Transactive memory system is a group-level concept, which refers to "the operation of the memory systems of the individuals and the processes of communication that occur within the group" (Wegner, 1987, p.191). It describes the active use of members' transactive memories to collaboratively complete a team task. The TMS plays an important role for knowledge intensive teams seeking to achieve high performance (Lewis, 2004). In a team with a well-developed TMS, team members can quickly identify and locate other colleagues with the knowledge most relevant to the issue at hand, which allows them to quickly contact and enlist the member best suited to perform a task or resolve a problem (Kotlarsky \& Oshri, 2005). Research on TMS has shown that for groups with a well-developed TMS, the individual cognitive load for each member is reduced by creating a greater pool of shared knowledge that is available to all team members (Wegner, 1987, 1995). Teams with a well-developed TMS allow members to specialize - thus developing deeper expertise in distinct domains, while also being able to quickly locate and enlist others whose expertise and skills are relevant to the issue at hand. As a result, teams with high levels of TMS execute their projects more effectively than ones with weaker TMSs (Austin, 2003; Lewis, 2004; Moreland \& Myaskovsky, 2000) and achieve better outcomes (Austin, 2003; Lewis, 2005).

One major benefit of a distributed team is access to diverse expertise across geographic locations (Majchrzak et al., 2004). However, due to a lack of face-to-face communication and personal interaction, it can be challenging for members to form highly developed TMSs, and inhibit their ability to access, share, and apply members' full scope of knowledge and expertise (Armstrong \& Cole, 1995; Cramton, 2001; Espinosa et al., 2007; Griffith \& Neale, 2001; Kotlarsky \& Oshri, 2005; Sole \& Edmondson, 2002).

We propose that the level of TMS is likely to be impaired when subgroups are perceived to exist in distributed teams. Subgroups can impair the development of a TMS in two ways. First, when members perceive strong subgroup formation, they are more likely to communicate and share information only with others within their own subgroup, but not with members of other subgroups (Cramton, 2001; Gratton, Voigt, \& Erickson, 2007; Polzer et al., 2006). This, in turn, makes it difficult for team members to be aware of the entire team's full range of expertise, which is an important aspect of TMS. Second, the existence of subgroups means that individuals cannot readily access other 
members' knowledge when they need it - especially knowledge held by members of other subgroups. In distributed environments, team members need to communicate project details and context-specific information to their fellow remote colleagues (Cramton, Orvis, \& Wilson, 2007). Thus, when subgroup formation discourages necessary communication and information sharing (Cramton, 2001; Gratton et al., 2007; Polzer et al., 2006), it also prevents the team from taking advantage of each other's expertise. Even if members are aware of a remote team member's knowledge and skills, they may not be able to obtain the clues needed to judge the credibility and quality of that person's knowledge and in turn they may misunderstand, ignore, or under-value available useful knowledge (Carlile 2002). Based on this logic, we propose that:

Hypothesis 2: Perceived subgroup formation is negatively related to TMSs in fully distributed teams.

\section{The Mediating Role of TMS in Fully Distributed Teams}

Compared to face-to-face teams, distributed teams are often more diverse in expertise and background (Griffith \& Neale, 2001). The ability to effectively leverage the expertise of members who reside in different locations is essential for the success of distributed teams (Majchrzak et al., 2004). Since TMS is a critical mechanism through which team members integrate and leverage each other's diverse expertise (Lewis, 2004), we propose that subgroup formation reduces team performance partly by impairing the development of TMS. Thus, including TMS as a mediator in our research model allows us to specify a mechanism through which perceived subgroup formation affects team performance.

Teams with well-developed TMSs perform better because members are aware of and can quickly locate knowledge across the entire group, which helps them effectively perform tasks in both face-toface teams (Austin, 2003; Lewis, 2004, 2005; Moreland \& Myaskovsky, 2000) and distributed teams (Kanawattanachai \& Yoo, 2007). However, as posited in Hypothesis 2, we expect that in the presence of perceived subgroups, distributed teams are less likely to achieve well-developed TMSs, which can impair performance. Therefore, in addition to having a direct negative impact on team performance, we expect perceived subgroup formation to also reduce performance by suppressing the development of a TMS. That is, we suggest that TMS is a "cognitive mediator" (Ilgen, Hollenbeck, Johnson, \& Jundt, 2005) by which perceived subgroup formation reduces team performance. We propose that the negative impact of perceived subgroup formation on team performance can be partly attributed to the negative effect of perceived subgroup formation on TMS. Thus, we propose that:

Hypothesis 3: A transactive memory system partially mediates the relationship between perceived subgroup formation and team performance in fully distributed teams.

\section{RESEARCH METHOD}

\section{Research Setting}

To test our research model, we collected survey data from students in an online MBA course over two semesters at a large university in the southeastern U.S. Nearly all the MBA students (i.e., 95 percent) in this online program hold full-time jobs during their studies and have an average of 6.6 years of work experience. To accommodate their different schedules, the course was administrated virtually through the online course management tool, Blackboard, in an asynchronized format with no faceto-face class meetings. As a major component of the course, students were organized into teams of four, and each team was required to submit three case study analyses during the semester; each case analysis accounted for 10 percent of their final grade. Each team could choose the three case studies (out of eight cases) they wanted to analyze and submit. For the case analysis, the students needed to identify the major issues presented in the case, use the assigned readings to guide their data analysis, offer recommendations, and prepare an action plan to implement their recommendations. Due to their 
various locations and work schedules, teams had to coordinate their work virtually, using various communication tools available in Blackboard (group discussion board, file exchange, chat room, and email), as well as other communications tools (non-Blackboard email, instant messenger and phone).

This course setting and team structure provided a context in which distributed students worked on knowledge intensive tasks but never met face-to-face. By stating that team members never met face-to-face, we do not imply that members were unaware of gender, age, profession, geographic location or other attributes of their teammates, since members are likely to mention these details when they "introduce" themselves to each other virtually. However, we consider our research setting as equivalent to fully distributed teams in the real world, where members do not meet face-to-face but are still aware of each other's demographic attributes and geographic location. Thus, we consider this online MBA program to be an ideal research setting to test our model. Given that team members needed time to become familiar with virtual collaboration practices and learn about other's expertise and working styles, the dataset analyzed here focuses on the survey that we administered after the teams had finished their third and final case analysis.

A total of 159 students were invited to participate in the study, of which 156 students (97 male, 59 female) completed our survey at the end of the course (98 percent response rate). Of the 156 respondents, 67.3 percent were located in different cities within the state where the university is located, while the rest of the students were located in other U.S. states or other countries (e.g., Italy, Japan). The students created their four-member teams by themselves at the start of the semester. Because a few students dropped the course, some teams had fewer than four members: out of 42 teams, 31 teams had four members, ten had three members, and one had two members. We removed the two-member team from our sample since, by definition, it is too small for a subgroup to form. This left a total of 41 teams consisting of three or four members for analysis.

\section{Measures}

We developed our survey following guidance in the literature. Whenever possible, we adapted validated measures from previous studies. The initial questionnaire was reviewed by a panel of five academic experts who were asked to evaluate content validity, clarity, question format, response format, appearance, and organization. We modified and re-organized the questionnaire according to their comments. Table 4 in Appendix A lists the constructs in the research model and their items.

\section{Perceived Subgroup Formation}

We created six items for this construct based on our review of literature (Cramton, 2001; Gratton et al., 2007; Panteli \& Davison, 2005; Polzer et al., 2006). We used these items to assess whether members recognized the emergence of subgroups and whether some members behaved as factions instead of as a cohesive group. The construct contains items such as "Communications (e.g., emails, phone calls) happened only among part of the group"; "One or more group members did not act like part of our group"; and "I withheld some project-related information from certain group members". Respondents rated all items on seven-point scales ( $1=$ strongly disagree to $7=$ strongly agree $)$.

\section{Transactive Memory System}

We measured TMS using Lewis' (2003) 15-item measure, which has been used in many TMS studies (Akgün, Byrne, Keskin, Lynn, \& Imamoglu, 2005; Jackson \& Moreland, 2009; Jarvenpaa \& Majchrzak, 2008; Lewis, 2004, 2005; Zhang et al., 2007). It contains items such as "Each group member has specialized knowledge of some aspect of our project"; "I was confident relying on the information that other group members brought to the discussion"; and "Our group had very few misunderstandings about what to do". Subjects scored these items on a seven-point scale ( 1 = strongly disagree to $7=$ strongly agree). 


\section{Team Performance}

We assessed team performance using Henderson and Lee's (1992) 5-item measure. The items ask respondents to evaluate their team's performance relative to other project teams on which they served, including dimensions like "efficiency of team operations"; "amount of work the group produced"; "group's adherence to schedules"; "quality of work the group produced"; and "ability to meet the goals of the project". We used a seven-point scale $(1=$ much lower than other teams and $7=$ much higher than other teams).

\section{Control Variables}

We included two control variables in our model. First, since prior research has shown that perceived interdependence among team members facilitates the level of a group's TMS (Hollingshead, 1998a; Hollingshead, 1998b; Hollingshead, 2001; Levine \& Moreland, 1999; Moreland, 1999; Wegner, Erber, \& Raymond, 1991), we included perceived task interdependence as a control for TMS. The underlying logic is that, in the absence of tasks requiring coordination among members, there is little need for TMS. We assessed interdependence using a 5-item measure developed by Campion et al. (1993), with a 7 -point scale ( $1=$ strongly disagree to $7=$ strongly agree $)$.

Second, we included past experience with distributed teams, as a control for team performance, since studies have shown that subjects with prior experience working in distributed teams had greater confidence working in such teams as well as higher levels of learning in such scenarios (Dineen, 2005). We measured this construct by asking, "How would you rate your level of experience working in distributed teams prior to the first group case study analysis?" Subjects were asked to choose among five answers specifying the number of the times they have worked in distributed teams ("I have never worked on such a team", "I have worked on 2-5 teams like that", etc.).

\section{ANALYSES AND RESULTS}

We followed four steps to analyze our data. First, we analyzed internal reliability, convergent validity, and discriminant validity, as well as common method bias to ensure the quality of our data. Second, we assessed interrater agreement to justify aggregating individual level data up to the group level. Third, we assessed predictive validity, checked for Simpson's paradox instances, and ruled out vertical and model-wide collinearity concerns in the research model. Fourth, we used structural equation modeling with WarpPLS 5.0 (Kock, 2015) to test the hypotheses. Table 1 presents the descriptive statistics for all constructs in the study.

\section{Measurement Validation, Common Method Bias, Aggregation Analysis and Model Validation}

Table 1 presents two metrics for internal reliability: Cronbach alpha and composite reliability. Both metrics support internal validity when the value exceeds 0.70 (Nunnally \& Bernstein, 1994). The results reported in Table 1 show high reliability for all constructs. Average variance extracted (AVE) was calculated to assess convergent validity and discriminant validity, which is achieved when the square root of each construct's AVE is larger than its correlation with other constructs (Gefen \& Straub, 2005; Gefen, Straub, \& Boudreau, 2000). Table 1 shows that discriminant validity was achieved. While we found the correlation between TMS and team performance to be 0.64 , this is still below the 0.8 threshold stated by Bagozzi et al. (1991), which indicates that TMS and team performance are distinct constructs. This correlation between TMS and team performance is also similar to results found in prior studies of TMS (Lewis, 2004). In addition, we conducted a principal components analysis (using varimax rotation) with all the items that were used to measure the three model constructs. The analysis yielded three factors and the result showed that all items loaded cleanly on the construct they 
Table 1. Means, SD, composite reliability AVE, full collinearity VIF and inter-construct correlations

\begin{tabular}{|l|l|l|l|l|l|l|l|l|c|}
\hline \multicolumn{1}{|c|}{ Variables } & $\begin{array}{l}\text { Mean } \\
\text { (SD) }\end{array}$ & $\begin{array}{l}\text { Cronbach } \\
\text { Alpha }\end{array}$ & $\begin{array}{c}\text { Composite } \\
\text { Reliability }\end{array}$ & AVE & $\begin{array}{c}\text { Full } \\
\text { Collin. } \\
\text { VIF }\end{array}$ & \multicolumn{1}{|c|}{$\mathbf{1}$} & $\mathbf{2}$ & $\mathbf{3}$ & $\mathbf{4}$ \\
\hline $\begin{array}{l}\text { 1. Perceived Subgroup } \\
\text { Formation }\end{array}$ & $\begin{array}{l}2.54 \\
(1.33)\end{array}$ & 0.94 & 0.95 & 0.77 & 1.98 & $\mathbf{0 . 8 8}$ & & & \\
\hline 2. TMS & $\begin{array}{l}5.44 \\
(0.53)\end{array}$ & 0.93 & 0.94 & 0.54 & 2.30 & $-0.49^{* *}$ & $\mathbf{0 . 7 3}$ & & \\
\hline 3. Team Performance & $\begin{array}{l}4.81 \\
(1.11)\end{array}$ & 0.97 & 0.98 & 0.90 & 2.38 & $-0.53^{* *}$ & $0.64^{* *}$ & $\mathbf{0 . 9 5}$ & \\
\hline $\begin{array}{l}\text { 4. Perceived Task } \\
\text { Interdependence }\end{array}$ & $\begin{array}{l}4.76 \\
(0.99)\end{array}$ & 0.83 & 0.89 & 0.67 & 1.23 & -0.09 & $0.22^{* *}$ & $0.19^{*}$ & $\mathbf{0 . 8 2}$ \\
\hline
\end{tabular}

Legend: ${ }^{*} p<.05,{ }^{* *} p<.01$ (2-tailed tests)

${ }^{a}$ All variables are measured with 7-point scales (larger numbers indicate higher values)

${ }^{\mathrm{b}} \mathrm{Bold}$ figures on the diagonal are values of the square root of the AVE

were intended to measure and did not cross-load on other constructs (factor loadings are reported in Appendix A), which shows high convergent and discriminate validity.

Since common method bias is generally acknowledged as a potential validity threat in behavioral research (Podasakoff, MacKenzie, Lee, \& Podsakoff, 2003), we considered the risk of common method bias throughout the research process. During survey design, we followed procedural remedies recommended by Podasakoff et al. (2003). We also used Harmon's one factor test to evaluate common method variance (Podasakoff \& Organ, 1986). The result of Harmon's one factor test indicates that no single factor accounted for a majority of the variance. Also, using the approach suggested by Podasakoff et al. (2003) and its application to PLS (Liang, Saraf, Hu, \& Xue, 2007), we included a marker variable (personal innovativeness with IT (Agarwal \& Prasad, 1998)) in the analysis. We chose this construct as a marker variable because it should be uncorrelated with other constructs in our model. This test showed that the mean common method variance was only 0.032 , compared to 0.618 (the mean variance explained by the other indicators). Taken together, these results demonstrate that common method bias is not a concern in our data.

Before computing team-level scores from individual member survey data, we assessed interrater agreement (IRA) within each team (Castro, 2002; James, Demaree, \& Wolf, 1984; James, Demaree, $\&$ Wolf, 1993; LeBreton \& Senter, 2008). The most common IRA index for multiple-item measures is the $r_{\mathrm{WG}(\mathrm{J})}$ index (James et al., 1984; James et al., 1993). We calculated $r_{\mathrm{WG}(\mathrm{J})}$ for each multi-item scale. The mean $\mathrm{r}_{\mathrm{WG}(\mathrm{J})}$ values are all above the 0.70 cutoff value (perceived subgroup formation = 0.88 , TMS $=0.88$, team performance $=0.89$, and perceived task interdependence $=0.82$ ). The $\mathrm{r}_{\mathrm{WG}(\mathrm{J})}$ values indicate that individual level scores for these constructs can be aggregated to the team level. We averaged member responses for each measure and used the mean value as team scores for hypothesis testing.

We also conducted a few tests using WarpPLS 5.0 (Kock, 2015) to assess predictive validity, check for Simpson's paradox instances, and rule out vertical and model-wide collinearity concerns in the research model. Since Q-squared coefficient for TMS (0.439) and team performance (0.589) are both greater than zero, the model presents acceptable predictive validity (Kock, 2015). Simpson's paradox ratio is 1 in our model, which means there are no instances of Simpson's paradox (Kock, 2015), indicating no causality problems (Pearl, 2009; Wagner, 1982).

In our research model, block variance inflation factor (VIF) was calculated for the link between perceived subgroup formation and team performance (1.683) and the link between TMS and team performance (1.638). Since both values are lower than 3.3, there is no vertical collinearity in the model (Kock \& Lynn, 2012). The full collinearity variance inflation factor was calculated for all 


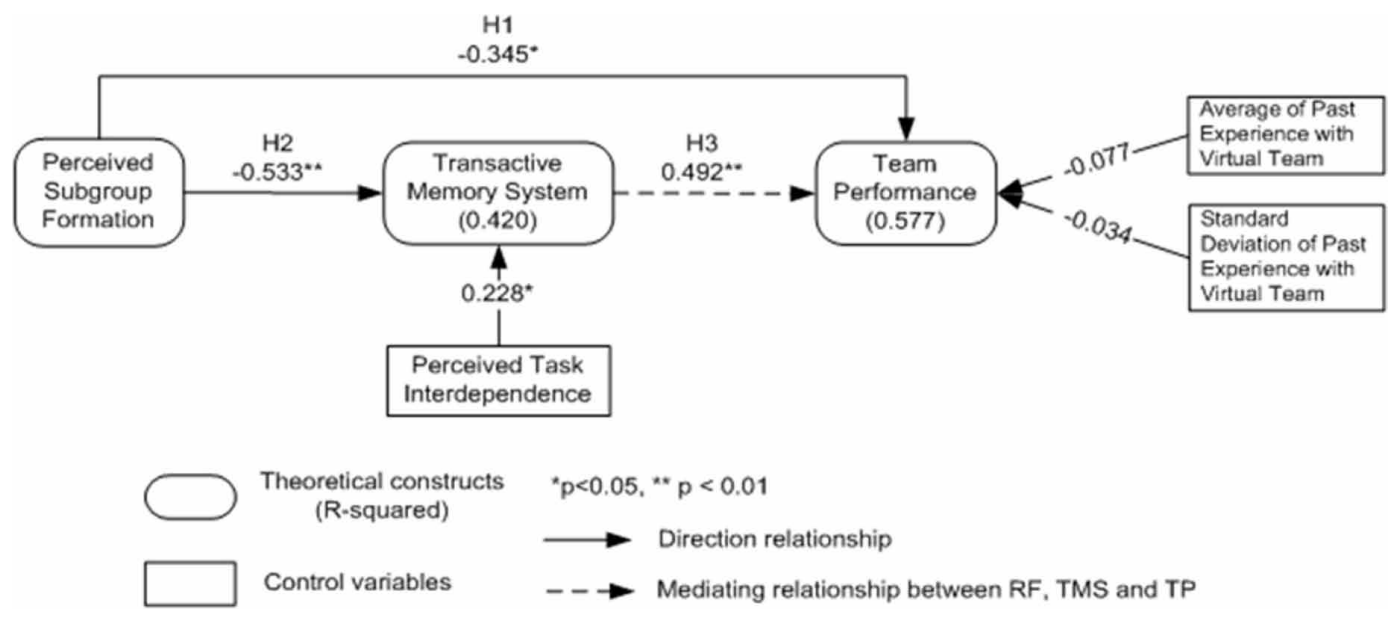

latent variables to assess model-wide collinearity. As reported in Table 1, the full collinearity VIF value for each variable is lower than the 3.3 threshold, indicating that the model is free of model-wide collinearity (Kock \& Lynn, 2012).

\section{Hypothesis Testing}

We used WarpPLS 5.0 (Kock, 2015) to test our research model. We used jackknifing to estimate the statistical significance of structural paths since jackknifing generates more stable results (i.e., resample path coefficients and $P$ values) with sample sizes smaller than 100 (Kock, 2011a, 2011b). Figure 2 shows standardized path coefficients and the explained variance $\left(\mathrm{R}^{2}\right)$ for each construct. The very high $\mathrm{R}^{2}$ value for the dependent variable -0.577 for team performance - indicates that our model explains a substantial amount of variance for team outcomes. We also found the control variable, perceived task interdependence, to be significantly related to TMS (path $=0.228, \mathrm{p}<0.05$ ). For the control variable, past experience with distributed teams, we calculated both the average of team members' past experience, and also the standard deviation for this past experience. We included both as controls for team performance; however, neither was related to team performance.

We first tested the hypothesis involving the direct effects corresponding to $\mathrm{H} 1$ and $\mathrm{H} 2$, based on the magnitude and significance of paths computed by WarpPLS. We found that the path from perceived subgroup formation to team performance (H1) was negative and statistically significant (path $=-0.345, \mathrm{p}<0.05)$. Thus, perceived subgroup formation is negatively related to team performance, confirming H1. Next, we found the path from perceived subgroup formation to TMS (H2) was negative and significant (path $=-0.533, \mathrm{p}<0.01$ ). Hence, $\mathrm{H} 2$ is also supported.

Table 2. Nested model comparison

\begin{tabular}{|l|l|l|l|l|l|l|}
\hline \multicolumn{2}{|c|}{ Direct Path } & $\begin{array}{c}\mathbf{R}^{2} \text { in Full } \\
\text { Mediation }\end{array}$ & $\begin{array}{c}\mathbf{R}^{2} \text { in Partial } \\
\text { Mediation }\end{array}$ & \multicolumn{1}{|c|}{$\Delta \mathbf{R}^{2}$} & \multicolumn{1}{c|}{$\mathbf{f}^{2}$ Value $^{\text {a }}$} & $\begin{array}{c}\text { Pseudo F }^{\text {b }} \\
\text { F (1, 36) }\end{array}$ \\
\hline H3 & $\begin{array}{l}\text { Perceived Subgroup Formation } \\
\rightarrow \text { Team Performance }\end{array}$ & 0.506 & 0.577 & 0.071 & 0.168 & $5.539 *$ \\
\hline
\end{tabular}

Legend: * $p<0.05$

${ }^{a} f^{2}=\left(R^{2}\right.$ in Partial Mediation $-R^{2}$ in Full Mediation $) /\left(1-R^{2}\right.$ in Partial Mediation $)$

${ }^{\text {bPseudo }} F=f^{2} x(n-k-1)$ with $1,(n-k)$ degrees of freedom. $N$ is the sample size and $k$ is number of constructs in the model 
Table 3. Significance of mediated paths

\begin{tabular}{|c|c|c|c|}
\hline \multicolumn{2}{|r|}{ Mediated Path } & \multirow{2}{*}{\begin{tabular}{r|} 
Path Mag. \\
-0.375
\end{tabular}} & \multirow{2}{*}{$\frac{\mathbf{Z}_{\text {stat }}}{\mathbf{b}}$} \\
\hline H3 & Perceived Subgroup Formation $\rightarrow$ TMS $\rightarrow$ Team Performance & & \\
\hline \multicolumn{4}{|c|}{ Legend: ${ }^{* *} p<0.01$} \\
\hline
\end{tabular}

In order to test the mediation effect of TMS on team performance (H3), we employed two complementary tests, following the procedure described by Subramani (2004). The first test compared two nested models: a partial mediation model (i.e., the model shown in Figure 1) and a full mediation model, where the direct path between perceived subgroup formation and team is omitted. The size and significance of the increased $\mathrm{R}^{2}$ statistic in the partial mediation model shows the increased explanatory power of the direct effect of the independent variable (perceived subgroup formation), in addition to the mediated path. We calculated the $\mathrm{f}^{2}$ statistic based on the changes in $\mathrm{R}^{2}$, and we used a pseudo F-test to evaluate the significance of the $\mathrm{f}^{2}$ (Chin, Marcolin, \& Newsted, 2003). Table 2 presents the results of comparing the nested models.

The second test of the strength of mediation analyzes the size and significance of the mediated path between the independent variable and the dependent variable in a full mediation model. Here, we examined the magnitude and variance of the direct paths among the independent variable, mediator, and dependent variable in a model that omits the direct path between the independent and dependent variables. Table 3 presents the results of the mediated path.

The results of hypothesis 1 testing show that the direct path between perceived subgroup formation and performance is significant ( $\mathrm{path}=-0.345, \mathrm{p}<0.05$ ). The results of the nested model comparison show that the direct influence of perceived subgroup formation on performance is also significant at $\mathrm{p}<0.05$ (Table 2). Analyses of individual mediated paths indicate that the mediated paths between perceived subgroup formation and TMS as well as that from TMS to team performance are negative and significant (Table 3). Based on our results, TMS partially (but not fully) mediates the effect of perceived subgroup formation on team performance. Thus, H3 is supported.

The hypothesis testing results reported above are based on the linear algorithm provided by WarpPLS. To test the possibility of nonlinear relationships, we also analyzed the same data set using a nonlinear algorithm provided by WarpPLS. The results were generally consistent with those using the linear algorithm, but showed that the relationships among latent variables were "warped", indicating potential nonlinear relationships in the model. Since WarpPLS 5.0 currently does not provide equations for nonlinear relationships, we cannot fully interpret the results. In addition, due to our relatively small sample size, we cannot exclude the possibility that the nonlinear relationships are due to some influential data points in the sample. Therefore, we would leave the further examination of the nonlinear relationships to future research.

\section{DISCUSSION}

This study contributes to the literature in three ways. First, this is the first empirical study to test the effects of perceived subgroup formation on TMS and team performance in fully distributed teams (where no members are colocated). By doing this, we answered the call for more research on subgrouplevel factors in distributed teams (Caya, Mortensen, \& Pinsonneault, 2013). Our findings confirm the proposition that subgroup dynamics within a team will shape both team processes and outcomes (Cramton, 2001; Cramton \& Hinds, 2005; Fiol \& O'Connor, 2005). Most prior studies of subgroups have focused on either face-to-face teams (Gibson \& Vermeulen, 2003; Jehn \& Bezrukova, 2010) or 
distributed teams, but where the subgroups were defined based on physical location only (O'Leary \& Mortensen, 2010; Polzer et al., 2006). Our study extends research on subgroups to distributed teams where each member exists in a distinct location and where members are unable to meet face-to-face. We found that in such teams, members' perceptions of subgroup formation impair both the team's level of TMS and its overall performance. This indicates that perceived subgroup formation is an indicator of the existence of subgroup divisions that are experienced by team members in such environments.

To the best of our knowledge, our study is the first field study to examine perceived subgroup formation in fully distributed teams. The two prior studies that considered subgroups in distributed teams were laboratory experiments, where researchers manipulated subgroups based on member geographic locations (O'Leary \& Mortensen, 2010; Polzer et al., 2006). Despite of their contribution to the literature, such artificial laboratory settings limit the generalizability of such results to real work settings. By conducting a survey with professionals working full-time, but collaborating on school-related projects, we are able to provide insights that can be applied to other real world settings.

Second, our study provides evidence of the role of TMS as a mediating construct between perceived subgroup formation and performance in distributed teams that work on knowledge intensive tasks. This means that, in addition to exerting a direct negative effect on team performance, members' perceptions of subgroups also impair team performance by preventing teams from developed a strong TMS, which is necessary for effective performance. The only studies to date that have examined mediators between perceived subgroup formation and team outcomes focused on the mediating role of conflict - both emotional conflict and intragroup conflict (Jehn \& Bezrukova, 2010; Pearsall, Ellis, \& Evans, 2008). Our study identified a distinct team-level construct that appears to serve as a cognitive mediator: TMS. Including TMS helps to provide a more complete explanation for how perceived subgroup formation can impair team performance, by reducing the level of informationsharing, coordination, and awareness of "who knows what."

Our findings, together with prior results (Jehn and Bezrukova, 2010; Pearsall et al., 2008) on various forms of conflict, also suggest that the relationship between the emergence of subgroups and group performance is more complex than is assumed in prior studies that only considered that subgroup divisions directly impair performance. Instead, our results show that in seeking to explain the negative effect of perceived subgroup formation on team performance, we should not focus just on its direct effects, but also consider how subgroups affect processes, such as TMSs, which, in turn, shape team outcomes.

Third, we extend the TMS literature to consider the influence of subgroup dynamics on TMS by introducing the concept of perceived subgroup formation. Prior research on TMS has not considered the impact of subgroup dynamics on the development of TMSs, either in face-to-face teams or in distributed teams. Leading research on team effectiveness has recently called for more research that examines the effect of team composition inputs on the development of TMS because "team composition inputs ... [are] likely to affect the ease with which members communicate and exchange information" (Ren \& Argote, 2011, p. 203). By including the notion of perceived subgroup formation in a field study of how TMS affects team performance, our study responds to this call by investigating the downstream effects of subgroups once they are perceived by team members. In doing so, we show that perceived subgroup formation is inversely associated with TMSs in distributed teams. Our study is the first to link the two formerly unrelated literatures on subgroups and TMS. Our findings contribute to the TMS literature by suggesting that the emergence of subgroups within a larger group is an important area to be considered in future research that examines TMSs.

Our findings provide managerial guidance on two fronts. On the first front, we suggest that managers should pay attention to factions that members perceive as existing within a distributed team, given the obstacles they pose to an effective TMS and to overall performance. Unlike face-to-face teams where subgroups based on members' demographic attributes are more obvious, managers of distributed teams may be oblivious to less salient subgroups that are perceived and experienced by team members. However, distributed teams are inherently diverse in nature. Such differences provide 
the potential for perceived subgroups to emerge. Our results suggest that managers should realize that it is possible for perceived subgroups to form in distributed teams, and that perceived subgroup formation has detrimental effects on team performance as well as on a critical team cognitive process: TMS. Managers can then try to minimize such divisions or reduce their impact by following advice appearing in the team management literature (especially prior studies on subgroups). For example, Gratton and colleagues advise managers to focus members' attention on performance goals and task completion in the early stage of a team's lifecycle, instead of dwelling on conflict and relationship issues among members (Gratton et al., 2007). A recent study suggests that redesigning a team's work structure can improve performance in teams with strong divisions (Rico, Sanchez-Manzanares, Antino, \& Lau, 2012).

Another implication is that team leaders should provide training and tools to help increase the level of TMS among team members. This is especially important given the fact that we were able to attribute the negative effect of subgroup factions on team performance partially to a team's decreased level of TMS. Although it may be more difficult to develop a TMS when perceived subgroup formation exists, and it may take longer for distributed teams to develop an effective TMS than face-to-face teams (Kanawattanachai \& Yoo, 2007), managers can strive to provide training and resources that facilitate initial TMS development. Research has shown that project activities and artifacts such as teleconferences (Oshri et al., 2008), online discussion boards (Choi, Lee, \& Yoo, 2010), videoconference-based project "kick-off" meetings and expertise directories (Moreland \& Myaskovsky, 2000), project homepages, and shared file space of previous conversations and shared experiences (Hollingshead, 1998b) can all facilitate TMS development in teams.

\section{LIMITATIONS AND FUTURE RESEARCH}

As with any empirical study, our approach has limitations. First, the data reported in this study represents cross-sectional data that was collected at a single point in time, without considering temporal effects. It will be useful to investigate the temporal nature of perceived subgroup formation on TMSs and team outcomes over time. Such longitudinal studies will provide insights into questions such as whether the initial perceptions that team members develop with regard to subgroups and TMSs in the early stages of a team's lifecycle differ from those in the middle or later stages of the team's lifecycle.

Second, we focused on the downstream effects of perceived subgroup formation on team processes and outcomes, without capturing upstream factors that may have contributed to such subgroup formation. Future research should specify events or problems that contribute to perceived subgroup formation, which may help managers detect and then minimize - or even avoid - such subgroups in distributed teams. This is especially useful for distributed teams, where demographic attributes that are easily observable in face-to-face teams become less salient, while geography, time zone, or other facets such as language or cultural distance are more prominent. Researchers have started to examine subgroups formed due to team member geographic locations (O'Leary \& Mortensen, 2010; Polzer et al., 2006), although they have not explored whether such formations are actually consistent with team members' perception of subgroups. Future research should explore whether the triggers to perceived subgroups formation in distributed teams could be based on geography, time zone, or other aspects of distance, including cultural or occupational differences.

Third, the data in our study are limited to the constructs in the survey that we administered to our respondents. Thus, we did not explore the teams' actual technology choices and their actual usage levels of various features to coordinate their work (e.g., email and discussion boards in Blackboard, telephone, and instant messenger) and how they affect team processes and outcomes. Studies have shown that in teams with diverse cultural backgrounds, specific information and communication technologies can mitigate the negative impact of cultural diversity on team performance (Shachaf, 2008). Researchers have also called for development of IT-based supports that can serve as substitutes for TMSs, in both colocated and distributed teams (Lewis \& Herndon, 2011). Recent research in 
this area has studied teleconferences (Oshri et al., 2008) and online discussion boards (Choi et al., 2010). Future research can explore whether and how the use of emerging Web 2.0 tools such as social networking sites, Wikis (Shu, Lin, \& Wang, 2015), and mobile applications may prevent or minimize the emergence of subgroups while optimizing the levels of TMSs in distributed teams.

Fourth, preliminary analysis using a nonlinear algorithm provided by WarpPLS 5.0 indicates potential nonlinear relationships in our research model. However, due to our relatively small sample size, we cannot exclude the possibility that the nonlinear relationships are due to some influential data points in the sample. Future research can explore whether nonlinear relationships exist among perceived subgroup formation, TMS and team performance.

\section{CONCLUSION}

Our research is motivated by the important role distributed teams play in today's organizations. Specifically, we investigated the effect of perceived subgroup formation, a factor that has received limited attention in distributed teams, on team processes and performance. We found that in distributed teams where members are located in different locations and members never meet face-to-face, perceived subgroup formation has a negative impact on team performance. Perceived subgroup formation also hurts team performance by discouraging teams from developing a transactive memory system (TMS), a critical team cognitive process that describes the active use of members' knowledge about what other members know to collaboratively complete team tasks. Based on results from our research, as well as other studies about team management (especially research on subgroups), below are a few actions that managers can take to alleviate the negative effects of perceived subgroup formation on distributed team performance (see Appendix B for a case that illustrates this in more detail).

First, unlike face-to-face teams where subgroups based on members' demographic attributes are more obvious, managers of distributed teams should be wary of the problems caused by the emergence of subgroups - which may be less visible or obvious in distributed teams. Second, to avoid subgroup divisions, managers should focus team members' attention on task completion and performance goals first, before dwelling on conflict and relationship issues among members (Gratton et al., 2007). Third, in an attempt to alleviate the negative influence of subgroup divisions that already exist in a team, managers can take actions to increase the level of transactive memory system (TMS) among team members. To achieve this purpose, researchers have recommended the use of teleconferences (Oshri et al., 2008), online discussion boards (Choi, Lee, \& Yoo, 2010), videoconference-based project "kick-off" meetings and expertise directories (Moreland \& Myaskovsky, 2000), project homepages, and shared file space of previous conversations and shared experiences (Hollingshead, 1998b).

\section{REFERENCES}

Agarwal, R., \& Prasad, J. (1998). A conceptual and operational definition of personal innovativeness in the domain of information technology. Information Systems Research, 9(2), 204-215. doi:10.1287/isre.9.2.204

Akgün, A. E., Byrne, J. C., Keskin, H., Lynn, G. S., \& Imamoglu, S. Z. (2005). Knowledge networks in new product development projects: A transactive memory perspective. Information \& Management, 42(8), 1105-1120. doi:10.1016/j.im.2005.01.001

Armstrong, D. J., \& Cole, P. (1995). Managing distances and differences in geographically distributed work groups. In S. Jackson \& M. Ruderman (Eds.), Diversity in work teams: Research paradigms for a changing workplace (pp. 187-215). Washington, DC: American Psychological Association. doi:10.1037/10189-007

Austin, J. R. (2003). Transactive memory in organizational groups: The effects of content, consensus, specialization, and accuracy on group performance. The Journal of Applied Psychology, 88(5), 866-878. doi:10.1037/0021-9010.88.5.866 PMID:14516250 
Bagozzi, R. P., Yi, Y., \& Phillips, L. W. (1991). Assessing construct validity in organizational research. Administrative Science Quarterly, 36(3), 421-458. doi:10.2307/2393203

Bhappu, A. D., Griffith, T. L., \& Northcraft, G. B. (1997). Media effects and communication bias in diverse groups. Organizational Behavior and Human Decision Processes, 70(3), 199-205. doi:10.1006/obhd.1997.2704

Bjørn, P., \& Ngwenyama, O. (2009). Virtual team collaboration: Building shared meanings, resolving breakdowns and creating translucence. Information Systems Journal, 19(3), 227-253. doi:10.1111/j.1365-2575.2007.00281.x

Campion, M. A., Medsker, G. J., \& Higgs, A. C. (1993). Relations between work group characteristics and effectiveness: Implications for designing effective work groups. Personnel Psychology, 46(4), 823-846. doi:10.1111/j.1744-6570.1993.tb01571.x

Carton, A. M., \& Cummings, J. N. (2012). A theory of subgroups in work teams. Academy of Management Review, 37(3), 441-470. doi:10.5465/amr.2009.0322

Castro, S. L. (2002). Data analytic methods for the analysis of multilevel questions: A comparison of intraclass correlation coefficients, $r_{w g}$, hierarchical linear modeling, within- and between analysis, and random group resampling. The Leadership Quarterly, 13(1), 69-93. doi:10.1016/S1048-9843(01)00105-9

Caya, O., Mortensen, M., \& Pinsonneault, A. (2013). Virtual teams demystified: An integrative framework for understanding virtual teams. International Journal of e-Collaboration, 9(2), 1-33. doi:10.4018/jec.2013040101

Chin, W., Marcolin, B., \& Newsted, P. (2003). A partial least squares latent variable modeling approach for measuring interaction effects: Results from a Monte Carlo simulation study and voice mail emotion/adoption study. Information Systems Research, 14(2), 189-217. doi:10.1287/isre.14.2.189.16018

Choi, S. Y., Lee, H., \& Yoo, Y. (2010). The impact of information technology and transactive memory systems on knowledge sharing, application, and team performance: A field study. Management Information Systems Quarterly, 34(4), 855-870.

Cramton, C. D. (2001). The mutual knowledge problem and its consequences for dispersed collaboration. Organization Science, 12(3), 346-371. doi:10.1287/orsc.12.3.346.10098

Cramton, C. D., \& Hinds, P. (2005). Subgroup dynamics in internationally distributed teams: Ethnocentrism or cross-national learning? Research in Organizational Behavior, 26, 231-263. doi:10.1016/S0191-3085(04)26006-3

Cramton, C. D., Orvis, K. L., \& Wilson, J. M. (2007). Situation invisibility and attribution in distributed collaborations. Journal of Management, 33(4), 525-546. doi:10.1177/0149206307302549

Cronin, M. A., Bezrukova, K., Weingart, L. R., \& Tinsley, C. H. (2011). Subgroups within a team: The role of cognitive and affective integration. Journal of Organizational Behavior, 32(6), 831-849. doi:10.1002/job.707

Davenport, T. H., \& Prusak, L. (1997). Working knowledge: How organizations manage what they know. Boston, MA: Harvard Business School Press.

Dineen, B. R. (2005). TeamXchange: A team project experience involving virtual teams and fluid team membership. Journal of Management Education, 29(4), 593-616. doi:10.1177/1052562905276275

Dougherty, D. (1992). Interpretive barriers to successful product innovation in large firms. Organization Science, 3(2), 179-202. doi:10.1287/orsc.3.2.179

Duranti, C. M., \& de Almeida, F. C. (2012). Is more technology better for communication in international virtual teams? International Journal of e-Collaboration, 8(1), 36-52. doi:10.4018/jec.2012010103

Earley, P. C., \& Mosakowski, E. (2000). Creating hybrid team culture: An empirical test of transnational team functioning. Academy of Management Journal, 43(1), 26-49. doi:10.2307/1556384

Elron, E., \& Shamir, B. (1999). Why don't they fight each other? Cultural diversity and operational unity in multinational forces. Armed Forces and Society, 26(1), 73-97. doi:10.1177/0095327X9902600105

Espinosa, J. A., Slaughter, S. A., Herbsleb, J. D., \& Kraut, R. E. (2007). Team knowledge and coordination in geographically distributed software development. Journal of Management Information Systems, 24(1), $135-169$. doi:10.2753/MIS0742-1222240104 
Espinosa, J. A., Slaughter, S. A., Kraut, R. E., \& Herbsleb, J. D. (2007). Familiarity, complexity and team performance in geographically distributed software development. Organization Science, 18(4), 613-630. doi:10.1287/orsc. 1070.0297

Fiol, C. M., \& O'Connor, E. J. (2005). Identification in face-to-face, hybrid, and pure virtual teams: Untangling the contradictions. Organization Science, 16(1), 19-32. doi:10.1287/orsc.1040.0101

Fuller, M. A., Hardin, A. M., \& Davison, R. M. (2006). Efficacy in technology-mediated distributed teams. Journal of Management Information Systems, 23(3), 209-235. doi:10.2753/MIS0742-1222230308

Gefen, D., \& Straub, D. W. (2005). A practical guide to factorial validity using PLS-Graph: Tutorial and annotated example. Communications of the AIS, 16, 91-109.

Gefen, D., Straub, D. W., \& Boudreau, M.-C. (2000). Structural equation modeling and regression: Guidelines for research practice. Communications of the AIS, 4(7).

Geller, D., Lee, C., Alonso, A., Schmit, M., \& Esen, E. (2012). Virtual Teams. Alexandria, VA: Society for Human Resource Management.

Gibson, C. B., \& Vermeulen, F. (2003). A healthy divide: Subgroups as a stimulus for team learning behavior. Administrative Science Quarterly, 48(2), 202-239. doi:10.2307/3556657

Glückler, J., \& Schrott, G. (2007). Leadership and performance in virtual teams: Exploring brokerage in electronic communication. International Journal of e-Collaboration, 3(3), 31-52. doi:10.4018/jec.2007070103

Gratton, L., Voigt, A., \& Erickson, T. (2007). Bridging faultlines in diverse teams. MIT Sloan Management Review, 48(4), 22-29.

Gressgard, J. L. (2011). Virtual team collaboration and innovation in organizations. Team Performance Management, 17(1/2), 102-119. doi:10.1108/13527591111114738

Griffith, T. L., \& Neale, M. A. (2001). Information processing in traditional, hybrid, and virtual teams: From nascent knowledge to transactive memory. Research in Organizational Behavior, 23, 379-421. doi:10.1016/ S0191-3085(01)23009-3

Harrison, D. A., Price, K. H., \& Bell, M. P. (1998). Beyond relational demography: Time and the effects of suface- and deep-level diversity on work group cohesion. Academy of Management Journal, 41(1), 96-107. doi: $10.2307 / 256901$

Henderson, J. C., \& Lee, S. (1992). Managing I/S design teams: A control theories perspective. Management Science, 38(6), 757-777. doi:10.1287/mnsc.38.6.757

Herbsleb, J. D., Mockus, A., Finholt, T., \& Grinter, R. E. (2000). Distance, dependencies, and delay in a global collaboration. Proceedings of the ACM Conference on Computer Supported Cooperative Work. New York, NY: ACM. doi:10.1145/358916.359003

Herbsleb, J. D., \& Moitra, D. (2001). Global software development. IEEE Software, 18(2), 16-20. doi: $10.1109 / 52.914732$

Hollingshead, A. B. (1998). Distributed expertise and communication processes in groups. In E. A. Mannix, M. A. Neale, \& D. H. Gruenfeld (Eds.), Research on managing groups and teams (Vol. 1). Greenwich, CT: JAI Press.

Hollingshead, A. B. (1998). Retrieval processes in transactive memory systems. Journal of Personality and Social Psychology, 74(3), 659-671. doi:10.1037/0022-3514.74.3.659

Hollingshead, A. B. (2001). Cognitive interdependence and convergent expectations in transactive memory. Journal of Personality and Social Psychology, 81(6), 1080-1089. doi:10.1037/0022-3514.81.6.1080 PMID:11761309

Homan, A. C., Hollenbeck, J. R., Humphrey, S. E., Van Knippenberg, D., Ilgen, D. R., \& Van Kleef, G. A. (2008). Facing differences with an open mind: Openness to experience, salience of intragroup differences, and performance of diverse work groups. Academy of Management Journal, 51(6), 1204-1222. doi:10.5465/ AMJ.2008.35732995 
Ilgen, D., Hollenbeck, J. R., Johnson, M., \& Jundt, D. (2005). Teams in organizations: From Input-Process-Output models to IMOI models. In S. T. Fiske, A. E. Kasdin, \& D. L. Schacter (Eds.), Annual review of psychology (Vol. 56, pp. 517-543). Palo Alto, CA. doi:10.1146/annurev.psych.56.091103.070250

Jackson, M., \& Moreland, R. L. (2009). Transactive memory in the classroom. Small Group Research, 40(5), 508-534. doi:10.1177/1046496409340703

James, L. R., Demaree, R. G., \& Wolf, G. (1984). Estimating within-group interrater reliability with and without response bias. The Journal of Applied Psychology, 69(1), 85-98. doi:10.1037/0021-9010.69.1.85

James, L. R., Demaree, R. G., \& Wolf, G. (1993). $\mathrm{r}_{\mathrm{wg}}$ : An assessment of within-group agreement. The Journal of Applied Psychology, 78(2), 306-309. doi:10.1037/0021-9010.78.2.306

Jarvenpaa, S. L., \& Leidner, D. E. (1999). Communication and trust in global virtual teams. Organization Science, 10(6), 791-815. doi:10.1287/orsc.10.6.791

Jarvenpaa, S. L., \& Majchrzak, A. (2008). Knowledge collaboration among professionals protecting national security: Role of transactive memories in ego-centered knowledge networks. Organization Science, 19(2), 260-276. doi:10.1287/orsc.1070.0315

Jarvenpaa, S. L., Shaw, T. R., \& Staples, D. (2004). Toward contextualized theories of trust: The role of trust in global virtual teams. Information Systems Research, 15(3), 250-267. doi:10.1287/isre.1040.0028

Jehn, K. A., \& Bezrukova, K. (2010). The faultline activation process and the effects of activated faultlines on coalition formation, conflict, and group outcomes. Organizational Behavior and Human Decision Processes, 112(1), 24-42. doi:10.1016/j.obhdp.2009.11.008

Kanawattanachai, P., \& Yoo, Y. (2007). The impact of knowledge coordination on virtual team performance over time. MIS Quarterly, 31(4), 783-808.

Kiesler, S., \& Cummings, J. N. (2002). What do we know about proximity in work groups? A legacy of research on physical distance. In P. Hinds \& S. Kiesler (Eds.), Distributed work (pp. 57-80). Cambridge, MA: MIT Press.

Kock, N. (2011a). Using WarpPLS in e-collaboration studies: Descriptive statistics, settings, and key analysis results. International Journal of e-Collaboration, 7(2), 1-18. doi:10.4018/jec.2011040101

Kock, N. (2011b). Using WarpPLS in e-collaboration studies: Mediating effects, control and second order variables, and algorithm choices. International Journal of e-Collaboration, 7(3), 1-13. doi:10.4018/jec.2011070101

Kock, N. (2015). WarpPLS 5.0 user manual. Laredo, TX: ScriptWarp Systems.

Kock, N., \& Lynn, G. S. (2012). Lateral collinearity and misleading results in variance-based SEM: An illustration and recommendations. Journal of the Association for Information Systems, 13(7), 546-580.

Kotlarsky, J., \& Oshri, I. (2005). Social ties, knowledge sharing and successful collaboration in globally distributed system development projects. European Journal of Information Systems, 14(1), 37-48. doi:10.1057/ palgrave.ejis. 3000520

Kotlarsky, J., van Fenema, P. C., \& Willcocks, L. P. (2008). Developing a knowledge-based perspective on coordination: The case of global software projects. Information \& Management, 45(2), 96-108. doi:10.1016/j. im.2008.01.001

Krauss, R., \& Fussell, S. (1990). Mutual knowledge and communicative effectiveness. In J. Galegher, R. E. Kraut, \& C. Egido (Eds.), Intellectual teamwork: The social and technological bases of cooperative work (pp. 111-144). Hillsdale, NJ: Erlbaum.

Kraut, R. E., \& Streeter, L. A. (1995). Coordination in software development. Communications of the ACM, 38(5), 69-81. doi:10.1145/203330.203345

LeBreton, J. M., \& Senter, J. L. (2008). Answers to 20 questions about interrater reliability and interrater agreement. Organizational Research Methods, 11(4), 815-852. doi:10.1177/1094428106296642

Levine, J. M., \& Moreland, R. L. (1999). Knowledge transmission in work groups: Helping newcomers to succeed. In L. L. Thompson, J. M. Levine, \& D. M. Messnick (Eds.), Shared cognition in organizations: The management of knowledge. London, U.K.: Lawrence Erlbaum. 
Lewis, K. (2003). Measuring transactive memory systems in the field: Scale development and validation. The Journal of Applied Psychology, 88(4), 587-604. doi:10.1037/0021-9010.88.4.587 PMID:12940401

Lewis, K. (2004). Knowledge and performance in knowledge-worker teams: A longitudinal study of transactive memory systems. Management Science, 50(11), 1519-1533. doi:10.1287/mnsc.1040.0257

Lewis, K., \& Herndon, B. (2011). Transactive memory systems: Current issues and future reseach directions. Organization Science, 22(5), 1254-1265. doi:10.1287/orsc.1110.0647

Lewis, K., Lange, D., \& Gillis, L. (2005). Transactive memory systems, learning and learning transfer. Organization Science, 16(6), 581-598. doi:10.1287/orsc.1050.0143

Li, J., \& Hambrick, D. C. (2005). Factional groups: A new vantage on demographic faultlines, conflict, and disintegration in work teams. Academy of Management Journal, 48(5), 794-813. doi:10.5465/AMJ.2005.18803923

Liang, H., Saraf, N., Hu, Q., \& Xue, J. (2007). Assimilation of enterprise systems: The effect of institutional pressure and the mediating role of top management. MIS Quarterly, 31(1), 59-87.

Lipponen, J., Kelkama, K., \& Juslin, M. (2003). Subgroup identification, superordinate identification and intergroup bias between the subgroups. Group Processes \& Intergroup Relations, 6(3), 239-250. doi:10.1177/13684302030063002

Lowry, P. B., Zhang, D., Zhou, L., \& Fu, X. (2010). Effects of culture, social presence, and group composition on trust in technology-supported decision-making groups. Information Systems Journal, 20(3), 397-315. doi:10.1111/j.1365-2575.2009.00334.x

Mahfooz, I. (2011). The State of Virtual Team Utilizaton in the 21st Century: A Research Survey by Chronos Consulting. Houston, TX: Chronos Consulting.

Majchrzak, A., Malhotra, A., \& Lipnack, J. (2004). Can absence make a team grow stronger. Harvard Business Review, 82(5), 131-137. PMID:15146742

Malhotra, A., \& Majchrak, A. (2004). Enabling knowledge creation in far-flung teams: Best practice for IT support and knowledge sharing. Journal of Knowledge Management, 8(4), 75-88. doi:10.1108/13673270410548496

Maruping, L., Zhang, X., \& Venkatesh, V. (2009). Role of collective ownership and coding standards in coordinating expertise in software project teams. European Journal of Information Systems, 18(4), 355-371. doi:10.1057/ejis.2009.24

Maznevski, M. L., \& DiStefano, J. J. (2000). Global leaders are team players: Developing global leaders through membership on global teams. Human Resource Management, 39(2/3), 195-209. doi:10.1002/1099050X(200022/23)39:2/3<195::AID-HRM9>3.0.CO;2-I

Molleman, E. (2005). Diversity in demographic characteristics, abilities and personality traits: Do faultlines affect team functioning? Group Decision and Negotiation, 14(3), 173-193. doi:10.1007/s10726-005-6490-7

Moreland, R. L. (1999). Transactive memory: Learning who knows what in work groups and organizations. In L. Thompson, D. Messick, \& J. Levine (Eds.), Shared cognition in organizations: The management of knowledge (pp. 3-31). Mahwah, NJ: Erlbaum.

Moreland, R. L., \& Myaskovsky, L. (2000). Exploring the performance benefits of group training: Transactive memory or improved communication? Organizational Behavior and Human Decision Processes, 82(1), 117-133. doi:10.1006/obhd.2000.2891

Mukherjee, D., Lahiri, S., Mukherjee, D., \& Billing, T. K. (2012). Leading virtual teams: How do cognitive, social, and behavioral capabilities matter? Management Decision, 50(2), 273-290. doi:10.1108/00251741211203560

Nunnally, J. C., \& Bernstein, I. H. (1994). Psychometric theory (3rd ed.). New York, NY, USA: McGraw-Hill, Inc.

O'Leary, M., \& Mortensen, M. (2010). Go (con)figure: Subgroups, imbalance, and isolates in geographically dispersed teams. Organization Science, 21(1), 115-131. doi:10.1287/orsc.1090.0434

Olson, G. M., \& Olson, J. S. (2000). Distance matters. Human-Computer Interaction, 15(1), 139-178. doi:10.1207/ S15327051HCI1523_4 
Orlikowski, W. J. (2002). Knowing in practice: Enacting a collective capability in distributed organizing. Organization Science, 13(3), 249-273. doi:10.1287/orsc.13.3.249.2776

Oshri, I., van Fenema, P. C., \& Kotlarsky, J. (2008). Knowledge transfer in globally distributed teams: The role of transactive memory. Information Systems Journal, 18(6), 593-616. doi:10.1111/j.1365-2575.2007.00243.x

Panteli, N., \& Davison, R. M. (2005). The role of subgroups in the communication patterns of global virtual teams. IEEE Transactions on Professional Communication, 48(2), 191-200. doi:10.1109/TPC.2005.849651

Pearl, J. (2009). Causality: Models, reasoning, and inference. Cambridge, England: Cambridge University Press. doi:10.1017/CBO9780511803161

Pearsall, M. J., Ellis, A. P. J., \& Evans, J. M. (2008). Unlocking the effects of gender faultlines on team creativity: Is activation the key? The Journal of Applied Psychology, 93(1), 225-234. doi:10.1037/0021-9010.93.1.225 PMID:18211148

Phillips, K. W., Mannix, E. A., Neale, M. A., \& Gruenfeld, D. H. (2004). Diverse groups and information sharing: The effects of congruent ties. Journal of Experimental Social Psychology, 40, 497-510. doi:10.1016/j. jesp.2003.10.003

Podasakoff, P. M., MacKenzie, S. B., Lee, J. Y., \& Podsakoff, N. P. (2003). Common method biases in behavioral research: A critical review of the literature and recommended remedies. The Journal of Applied Psychology, 88(5), 879-903. doi:10.1037/0021-9010.88.5.879 PMID:14516251

Podasakoff, P. M., \& Organ, D. W. (1986). Self-reports in organizational research: Problems and perspectives. Journal of Management, 12(4), 531-544. doi:10.1177/014920638601200408

Polzer, J. T. (2004). How subgroup interests and reputation moderate the effect of organizational identification on cooperation. Journal of Management, 30(1), 71-96. doi:10.1016/j.jm.2002.12.003

Polzer, J. T., Crisp, C. B., Jarvenpaa, S. L., \& Kim, J. W. (2006). Extending the faultline model to geographically dispersed teams: How colocated subgroups can impair group functioning. Academy of Management Journal, 49(4), 679-692. doi:10.5465/AMJ.2006.22083024

Purvanova, K. R., \& Bono, E. J. (2009). Transformational leadership in context: Face-to-face and virtual teams. The Leadership Quarterly, 20(3), 343-357. doi:10.1016/j.leaqua.2009.03.004

2011. RW3 CultureWizard. (2014). Trends in Global Virtual Teams. New York, NY: RW3 LLC.

Ren, Y., \& Argote, L. (2011). Transactive memory systems 1985-2010: An integrative framework of key dimensions, antecedents, and consequences. The Academy of Management Annals, 5(1), 189-229. doi:10.108 $0 / 19416520.2011 .590300$

Rico, R., Molleman, E., Sanchez-Manzanares, M., \& Vegt, G. S. V. (2007). The effects of diversity faultlines and team task autonomy on decision quality and social integration. Journal of Management, 33(1), 111-132. doi:10.1177/0149206306295307

Rico, R., Sanchez-Manzanares, M., Antino, M., \& Lau, D. (2011). Bridging team faultlines by combining task role assignment and goal structure strategies. The Journal of Applied Psychology, 97(2), 407-420. doi:10.1037/ a0025231 PMID:21875173

Sarker, S., Ahuja, M., Sarker, S., \& Kirkeby, S. (2011). Revisiting the role of trust and communication in globallydistributed teams: A social network analysis perspective. Journal of Management Information Systems, 28(1), 273-309. doi:10.2753/MIS0742-1222280109

Shachaf, P. (2008). Cultural diversity and information and communication technology impacts on global virtual teams: An exploratory study. Information \& Management, 45(2), 131-142. doi:10.1016/j.im.2007.12.003

Shu, W., Lin, H. C.-S., \& Wang, G. (2015). Inter-group collaboration: Factoring technology characteristics and task type. International Journal of e-Collaboration, 11(2), 28-46. doi:10.4018/ijec.2015040103

Snow, C., Snell, S., Davison, S. C., \& Hambrick, D. C. (1996). Using transnational teams to globalize your company. Organizational Dynamics, 24(4), 50-76. doi:10.1016/S0090-2616(96)90013-3 
Sole, D., \& Edmondson, A. (2002). Situated knowledge and learning in dispersed teams. British Journal of Management, 13(S2), 17-34. doi:10.1111/1467-8551.13.s2.3

Storck, J., \& Hill, P. A. (2000). Knowledge diffusion through "strategic communities". Sloan Management Review, 41(2), 63-74.

Subramani, M. (2004). How do suppliers benefit from information technology use in supply chain relationships? MIS Quarterly, 28(1), 45-73.

Thomas, D., \& Bostrom, R. (2010). Team leader strategies for enabling collaboration technology adaptation: Team technology knowledge to improve globally distributed systems development work. European Journal of Information Systems, 19(2), 223-237. doi:10.1057/ejis.2010.14

Wagner, C. H. (1982). Simpson's paradox in real life. The American Statistician, 36(1), 46-48.

Wegner, D. M. (1987). Transactive memory: A contemporary analysis of the group mind. In B. Mullen \& G. R. Goethals (Eds.), Theories of group behavior (pp. 185-208). New York: Springer-Verlag. doi:10.1007/9781-4612-4634-3_9

Wegner, D. M. (1995). A computer network model of human transactive memory. Social Cognition, 13(3), 319-339. doi:10.1521/soco.1995.13.3.319

Wegner, D. M., Erber, R., \& Raymond, P. (1991). Transactive memory in close relationship. Journal of Personality and Social Psychology, 61(6), 923-929. doi:10.1037/0022-3514.61.6.923 PMID:1774630

Zhang, Z. X., Hempel, P. S., Han, Y. L., \& Tjosvold, D. (2007). Transactive memory system links work team characteristics and performance. The Journal of Applied Psychology, 92(6), 1722-1730. doi:10.1037/00219010.92.6.1722 PMID:18020808

Yide Shen is an assistant professor of MIS in the Marketing and Business Information Systems Department at Rohrer College of Business, Rowan University. She received her Ph.D. in Computer Information Systems at Georgia State University. She also holds a M.S. in Management Information Systems from University of Nebraska at Omaha. Her research articles appear in referred journals and conferences including Decision Support Systems, the International Conference on Information Systems, and the Americas Conference on Information Systems. Her current research interests include coordination effectiveness for distributed teams, individual decision-making in IT project and information systems pedagogy.

Michael (Mike) J. Gallivan is an Associate Professor in Georgia State University's Computer Information Systems Department. He holds a Ph.D. from MIT, an MBA and MHA from the University of California, Berkeley, and a BA from Harvard University. He has served as an Associate Editor and Guest Senior Editor for MIS Quarterly, as well as an Associate Editor for Journal of Information Technology and Journal of Management Information Systems. His work has been published in various journals, including Database for Advances in Information Systems, European Journal of Information Systems, IEEE Transactions on Professional Communication, Information \& Management, Information and Organization, Information Systems Journal, Information Technology \& People, Journal of Management Information Systems, Journal of the Association for Information systems, MIS Quarterly, and MISQ Executive.

Xinlin Tang is an Associate Professor of Management Information Systems at the College of Business, Florida State University. She holds a Ph.D. from Georgia State University. Her current research focuses on digitally enabled business network management, IT-enable innovation and business value, and IT-enable knowledge management. Her research has been published or forthcoming in a number of high-impact journals and conference proceedings, including Information Systems Research, Journal of Management Information Systems, Journal of Operations Management, IEEE Transactions on Engineering Management, and International Conference on Information Systems (ICIS). 


\section{APPENDIX A}

Table 4. Measurement items and factor loadings

\begin{tabular}{|c|c|c|}
\hline $\begin{array}{l}\text { Construct } \\
\text { (Source) }\end{array}$ & Item & $\begin{array}{l}\text { Factor } \\
\text { Loading }\end{array}$ \\
\hline \multirow{6}{*}{$\begin{array}{l}\text { Perceived } \\
\text { subgroup } \\
\text { division } \\
\text { (New scale) }\end{array}$} & 1. Communications (e.g., emails, phone calls) happened only among part of the group & 0.702 \\
\hline & $\begin{array}{l}\text { 2. I found it easier to communicate (e.g., sending emails, talking on the phone) with } \\
\text { certain group members than others }\end{array}$ & 0.726 \\
\hline & $\begin{array}{l}\text { 3. I preferred to ask project related information from certain group members over } \\
\text { others }\end{array}$ & 0.714 \\
\hline & 4. One or more group members did not act like part of our group & 0.769 \\
\hline & 5. I withheld some project-related information from certain group members & 0.700 \\
\hline & $\begin{array}{l}\text { 6. If one or more group members were omitted from our group, it would have been } \\
\text { much easier to finish this project }\end{array}$ & 0.746 \\
\hline \multirow{15}{*}{$\begin{array}{l}\text { Transactive } \\
\text { Memory System } \\
\text { (Lewis 2003) }\end{array}$} & 1. Each group member has specialized knowledge of some aspect of our project & 0.729 \\
\hline & 2. I have knowledge about an aspect of the project that no other member has & 0.828 \\
\hline & 3. Different group members are responsible for expertise in different areas & 0.824 \\
\hline & $\begin{array}{l}\text { 4. The specialized knowledge of several different group members was needed to } \\
\text { complete the project deliverable }\end{array}$ & 0.857 \\
\hline & 5. I know which group members have expertise in specific areas & 0.792 \\
\hline & 6. I was comfortable accepting procedural suggestions from other group members & 0.783 \\
\hline & 7. I trusted that other members' knowledge about the project was credible & 0.811 \\
\hline & $\begin{array}{l}\text { 8. I was confident relying on the information that other group members brought to the } \\
\text { discussion }\end{array}$ & 0.817 \\
\hline & $\begin{array}{l}\text { 9. When other members gave information, I wanted to double-check it for myself } \\
\text { (reversed) }\end{array}$ & 0.585 \\
\hline & 10. I did not have much faith in other members' "expertise" (reversed) & 0.611 \\
\hline & 11. Our group worked together in a well-coordinated fashion & 0.690 \\
\hline & 12. Our group had very few misunderstandings about what to do & 0.659 \\
\hline & $\begin{array}{l}\text { 13. Our group needed to backtrack and repeat certain parts of the project a lot } \\
\text { (reversed) }\end{array}$ & 0.606 \\
\hline & 14. We accomplished the task smoothly and efficiently & 0.707 \\
\hline & 15. There was much confusion about how we would accomplish the task (reversed) & 0.771 \\
\hline \multirow{5}{*}{$\begin{array}{l}\text { Team } \\
\text { Performance } \\
\text { (Henderson \& } \\
\text { Lee, 1990) }\end{array}$} & 1. Efficiency of team operations & 0.815 \\
\hline & 2. Amount of work the group produced & 0.880 \\
\hline & 3. Group's adherence to schedules & 0.780 \\
\hline & 4. Quality of work the group produced & 0.879 \\
\hline & 5. Ability to meet the goals of the project & 0.823 \\
\hline
\end{tabular}




\section{APPENDIX B}

A Case of Perceived Subgroups Formation in a Distributed Team and Recommendations for Managers

Is it possible for subgroups to emerge in distributed teams? To illustrate the possibility of perceived subgroups forming in a distributed team, consider a work team with four members, where each member worked from a different location. All four members worked for the same company but they came from different functional areas and had different levels of tenure within the company. As team members got to know each other through emails and other technology-mediated communications (e.g., Skype calls, instant messages), they started to realize the similarities and differences among them, from which subgroups can form. For example, two younger members who recently joined the company discovered that the other two members who had been with the company for more than a decade were slow at responding to work related instant messages. As a result, some decisions were quickly made by the two newer members on the team, even before the older team members had a chance to voice their opinions. In this example, subgroups form based on age and the level of tenure with the company.

Can subgroup divisions be harmful to teams? Continuing with the example above, when the longer-tenure subgroup realized that they were left out of some team decisions, they began to feel isolated and felt that the younger members lacked respect for their opinions. This became a source of tension and conflict between the two subgroups. Each pair of team members started to share information only within their subgroup (i.e., the two younger members, and the two older members). As a result, it became difficult for all the team members to know member skills and expertise from the other subgroup, the current status of tasks that the members of the other subgroup were performing, the challenges that those performing them faced in completing those tasks, or ways to resolve similar challenges when they arose in their own work. This reflects a low level of transactive memory system (TMS) within the overall team, as members became less aware of what knowledge other subgroup members possess, what other subgroup members were doing or how they were doing it. Members began to waste time, by duplicating tasks that others had already performed or tried to derive a solution to a problem that another team member had already encountered and resolved. Eventually, the team's overall performance began to suffer due to a lack of awareness, communication, and coordination across the full team (even though each pair of members in a subgroup were still communicating well with each other).

What should managers do to minimize such divisions or reduce their impact on teams? Our research, as well as other studies about team management (especially research on subgroups) provides advice for managers to minimize the risk of subgroup formation and the related problems, including:

1. Pay attention to the possibility that subgroups can form, even in distributed teams where demographic attributes are less noticeable (e.g., age, race). In distributed teams, subgroups can form based on these and other factors, including tenure with the company; generational groups (e.g., Generation X vs. Y); the existence of prior relationships among some members; and members' attitudes, beliefs, and personalities (Harrison, Price, \& Bell, 1998; Polzer, 2004). Look for signs of subgroup formation such as employees referring to "us vs. them", communications (e.g., emails, phone calls) that occur among just part of the team, and one or more members complaining of feeling isolated;

2. To bridge subgroup divisions, managers should focus team members' attention on task completion and performance goals first, before dwelling on conflict and relationship issues among members (Gratton, Voigt, \& Erickson, 2007). The rationale is, when teams are new, besides conventional kick-off meetings, managers should not emphasize the social aspects of the team, which creates opportunities for members to "make snap judgments and to emphasize their differences" (Gratton et al., 2007, p. 26). Instead, concentrating on taskoriented goals helps team members learn each other's skills and expertise (this is consistent 
with our finding of the need to increase the level of transactive memory system) rather than emphasizing differences in personalities, work styles and other aspects. Over time, if subgroup divisions still emerge, managers should shift the task orientation emphasis to a relationship orientation. For example, managers can organize social activities for members to know each other, to talk about and show respect for any differences in values and work styles (Gratton et al., 2007). In fully distributed teams, this can be achieved by organizing face-to-face events when a team's budget allows, or by devoting sometime in audio or videoconferences for social aspects of the team if travel is not possible;

3. In an attempt to alleviate the negative influence of subgroup divisions that already exist in a team, managers can take actions to increase the level of transactive memory system (TMS) among team members. This is because perceived subgroup formation also reduces performance by suppressing the development of TMS, which is necessary for distributed teams to perform effectively. It may take longer for distributed teams to develop an effective TMS than face-to-face teams (Kanawattanachai \& Yoo, 2007), but managers can still use various means to facilitate TMS development in teams. The main idea is to make it easier for team members to learn what other members know, to obtain clues to help them judge the credibility and quality of others' knowledge. To achieve this goal, researchers have recommended the use of teleconferences (Oshri, van Fenema, \& Kotlarsky, 2008), online discussion boards (Choi, Lee, \& Yoo, 2010), videoconference-based project "kick-off" meetings and expertise directories (Moreland \& Myaskovsky, 2000), project homepages, and shared file space of previous conversations and shared experiences (Hollingshead, 1998). 